\title{
Cystatin C Peptide Effects on B16F10 Melanoma Cells
}

\section{Mathieu Hill, James L. Cox}

AT Still University, Department of Biochemistry, West Jefferson, Kirksville, Missouri, USA

Email: jcox@atsu.edu

How to cite this paper: Hill, M. and Cox, J.L. (2021) Cystatin C Peptide Effects on B16F10 Melanoma Cells. CellBio, 10, 1-9. https://doi.org/10.4236/cellbio.2021.101001

Received: December 19, 2020

Accepted: March 14, 2021

Published: March 17, 2021

Copyright $\odot 2021$ by author(s) and Scientific Research Publishing Inc. This work is licensed under the Creative Commons Attribution-NonCommercial International License (CC BY-NC 4.0). http://creativecommons.org/licenses/by-nc/4.0/ cc) (i) (8) Open Access

\begin{abstract}
Background: Metastasis is a major problem for effective therapy of cancer. Small cysteine protease inhibitors, cystatins have been shown to be anti-metastatic for a number of different cancers. We have identified a small peptide of cystatin which exhibits anti-cancer properties for B16 melanoma cells in vitro. Methods: B16 melanoma cells were measured for growth, proliferation, migration, and apoptosis in the presence and absence of cystatin peptide. Results: The cystatin peptide reduced melanoma cell growth, proliferation, migration, and increased apoptosis in melanoma cells in culture. Conclusion: Cystatin peptide exhibits anti-cancer effects on highly metastatic B16 melanoma cells in culture.
\end{abstract}

\section{Keywords \\ Cystatin, Peptide, Melanoma, Metastasis}

\section{Introduction}

Metastasis is a major problem to overcome with current cancer treatments such as chemotherapy and radiation. The object of cancer therapy is elimination of all tumor cells but often cancer cell resistance to therapy develops and results in tumor regrowth following therapy. New strategies will involve drug combinations against targets that prevent resistance or that target metastasis itself. An example could be the targeting of signal pathways driving metastasis to arrest cancer spread. Arresting cancer spread is cytostatic and would probably require continuous delivery of the affective agent to the cancer patient. Far better is the therapeutic induction of cell death of metastatic cancer cells so that secondary growth of metastatic cells could be greatly reduced or eliminated.

Cystatins are natural cysteine protease inhibitors that primarily inhibit ca- 
thepsins [1]. The role of cystatins in cancer is of interest because some cathepsin levels are invariably increased during cancer progression. Cathepsins play roles in multiple aspects of invasive cancer cells and therefore are key targets by either cystatins or selective chemical inhibitors [2]. A number of groups have shown cystatins are anti-metastatic experimentally for several different cancer types, although the mechanisms involved are still unclear [3] [4] [5]. From work on cystatins and cancer, it is clear cystatins can act in ways unrelated to their roles as cathepsin inhibitors [6]. Our previous work showed cystatin $C$ could inhibit melanoma metastasis by blocking cancer cell migration/invasion and induction of apoptosis [7]. We have since uncovered an anti-metastatic region of cystatin C that does not act as a protease inhibitor [8]. We had a short cystatin peptide synthesized from this region and describe in this work the effect of this cystatin peptide on B16F10 melanoma cells in vitro.

\section{Materials and Methods}

Cells B16F10 melanoma cells were purchased from ATCC. RPMI 1640 (Cambrex) media containing 10\% fetal bovine serum (Atlanta Biologicals) and $1 \%$ antibiotic solution (100 IU $/ \mathrm{ml}$ penicillin, $100 \mu \mathrm{g} / \mathrm{ml}$ streptomycin, $0.25 \mu \mathrm{g} / \mathrm{ml}$ amphotericin) (Sigma Chemical) was used to culture cells.

Peptide Cystatin peptide was designed as $\mathrm{N}$-terminal penetratin linked to first hairpin loop of mouse cystatin C [9]. Peptide with sequence RQIKIWFPNRRMKWKKAYRKQLVAGVNYFFDVH was ordered from Peptide 2.0 and received at $97 \%$ purity. Stock peptide concentration at $1 \mathrm{mM}$ in sterile water was stored frozen at $-80^{\circ} \mathrm{C}$ until use. Scrambled peptide was scrambled for the cystatin part and not the penetratin part, also ordered from Peptide 2.0.

Western blots Melanoma cells were grown under standard conditions, media removed and cells lysed with lysis buffer containing protease inhibitors. Proteins were separated on a $10 \%$ SDS-polyacrylamide gel and transferred to PVDF membrane at 100 volts for 1 hour. Blots were then blocked with Intercept ${ }^{\mathrm{TM}}$ blocking buffer and probed with primary rabbit antibodies to pMARCKS and actin both at 1:1000 dilution. Blots were washed with PBST buffer containing $0.1 \%$ Tween 20 and probed with secondary antibodies (1:10,000 dil.) which were anti-rabbit IR-800 (LiCor).

MTT assay

For measuring cell growth with peptide treatments, $5 \times 10^{3}$ cells in $100 \mu \mathrm{L}$ of RPMI complete media were plated in 96 well plates with 3 wells per treatment. The experiment consisted of wells seeded with cells for 72 hours growth period. After growth, media was removed and replaced with $10 \%$ MTT stock solution (5 $\mathrm{mg} / \mathrm{mL}$ ) with $90 \%$ complete RPMI media, followed by incubation at $5 \% \mathrm{CO}_{2}$ and $37^{\circ} \mathrm{C}$ for 4 hours. After incubation, the MTT solution was removed and $100 \mu \mathrm{L}$ of isopropanol was added. The plate was then placed on a plate rocker at $30 \times$ speed for 15 minutes at room temperature, foil covered. Absorbance readings 
were then measured immediately at $570 \mathrm{~nm}$. Each assay was performed in triplicate, and data is presented as means \pm standard error.

Cell proliferation assay Cells were plated at $8 \times 10^{3}$ cells per well in 96 well plates. Cells were then treated with 0,10 , or $20 \mu \mathrm{M}$ peptide for 24 hours at $37^{\circ}$. The Biovision BrdU Cell Proliferation kit was used and instructions were followed with 1 hour BrdU labeling time and 10-minute HRP-linked antibody reaction time [10]. Assays were done for triplicate experiments.

Migration assay (Scratch assay) Cells were seeded in a 24-well plate at a density of $3 \times 10^{5}$ cells per well for 16 hours in media. Cells were scratched in a straight line, perpendicular to a reference line, with a $200 \mu \mathrm{L}$ yellow pipette tip in three places in order to create cell-free strips (wounds). Media from each well was replaced after all three scratches were made. Digital images were taken immediately after performing the scratches and after 24 hours. Microscopy was performed with an Olympus inverted microscope using the $4 \times$ objective. Digital images of cells on the glass coverslips were captured with a Motic ${ }^{\mathrm{TM}}$ digital camera and Motic images plus ML application software (version 2.0). When using the $4 \times$ objective, the field-of-view was $1830 \mu \mathrm{m} \times 1464 \mu \mathrm{m}$ at the detection surface of the camera. Cell migration was measured by change in scratch-wound closure by the following formula: ((Time zero area - Time $24 \mathrm{hr}$ area)/( $2 \times$ 1830)).

TUNEL assay Apoptosis level was determined by the terminal deoxynucleotide transferase (TUNEL) assay using a kit from BioVision. B16F10 melanoma cells $\left(1 \times 10^{4}\right)$ were treated in 8 -chamber glass slides for 48 hours at $37^{\circ} \mathrm{C}$ with or without peptide before fixing the cells with $4 \%$ paraformaldehyde for 15 minutes and twice washing with PBS. The TUNEL assay with BrdU labeling was performed according to the instructions from BioVision, but on fixed cells [11]. Cells were imaged with a Zeiss fluorescent microscope. Total cells per field were taken as the PI positive nuclei. Apoptotic cells were counted as green fluorescent "cell remnants". The percentage of apoptotic cells was calculated from apoptotic cells/total nuclei $\times 100$.

\section{Results}

Based on a report that Wnt 5a/PKC pathway drives cell migration of melanoma, we tested whether cystatin overexpression could inhibit PKC $\alpha$ activity in B16 melanoma cells [12]. Figure 1 shows MARCKS (myristoylated alanine-rich C kinase substrate) protein phosphorylation is inhibited upon cystatin C overexpression in two independent B16 melanoma clones isolated in previous work [8]. MARCKS protein is a key target of $\mathrm{PKC} \alpha$ phosphorylation and also a major player in melanoma cell migration [13].

A short peptide was synthesized to a region of cystatin C (QLVAG region) responsible for the anti-invasion property of cystatin [8]. When this peptide was incubated with B16F10 melanoma cells under growth conditions there was decreased net cell growth after 72 hours (Figure 2). The decreased net cell growth 
could be due to inhibition of cell proliferation or increased cell death or both by the peptide. To examine this point further, a cell proliferation assay was done in the presence or absence of the peptide (Figure 3 ). We found a dose dependent inhibition of cell proliferation by the cystatin peptide on the B16 melanoma cells in culture. About a $50 \%$ inhibition of BrdU positive cells in culture was noted at $20 \mu \mathrm{M}$ cystatin peptide. Cell migration was also inhibited by the peptide applied to cells in culture. Figure 4 shows decreased migration of B16 melanoma cells in a scratch assay in the presence of the cystatin peptide relative to a scrambled peptide. Another aspect of peptide effects on melanoma cells in culture was that of cell death induction. Apoptosis can be measured with a TUNEL (terminal deoxynucleotidyl transferase dUTP nick end labeling) assay [11]. In Figure 5, we found about a ten-fold increase in apoptosis by TUNEL assay with $20 \mu \mathrm{M}$ cystatin peptide after 48 -hour melanoma cell treatment at $37^{\circ} \mathrm{C}$. This level of apoptosis is not massive but represents cell death of at least $10 \%-20 \%$ of the original melanoma cell population.

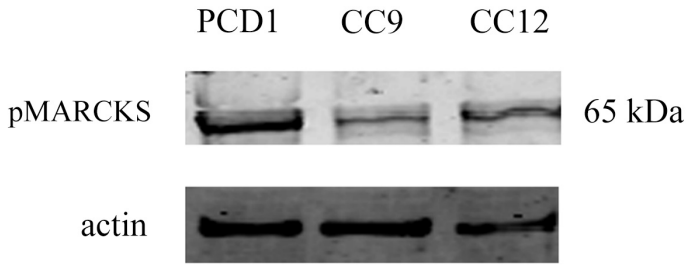

Figure 1. Cystatin C overexpression inhibits MARCKS phosphorylation. Western blot analysis of MARCKS phosphorylation. Two different cystatin $\mathrm{C}$ overexpressing clones, CC9 and CC12 along with pcDNA3 empty vector clone (PCD1) were probed with antibody to pMARCKS. Actin was used as a loading control.

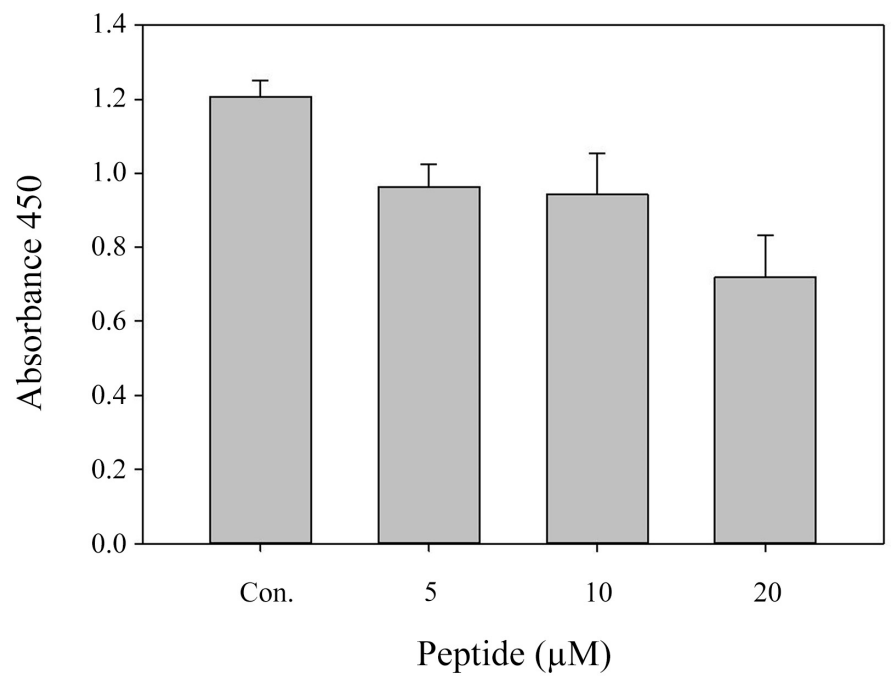

Figure 2. Growth of cells treated with cystatin C peptide. MTT assay on B16F10 melanoma cells after 72 hours growth with $0,5,10$, or $20 \mu \mathrm{M}$ cystatin peptide. Assays were done in triplicate and values represent the average of three experiments. 


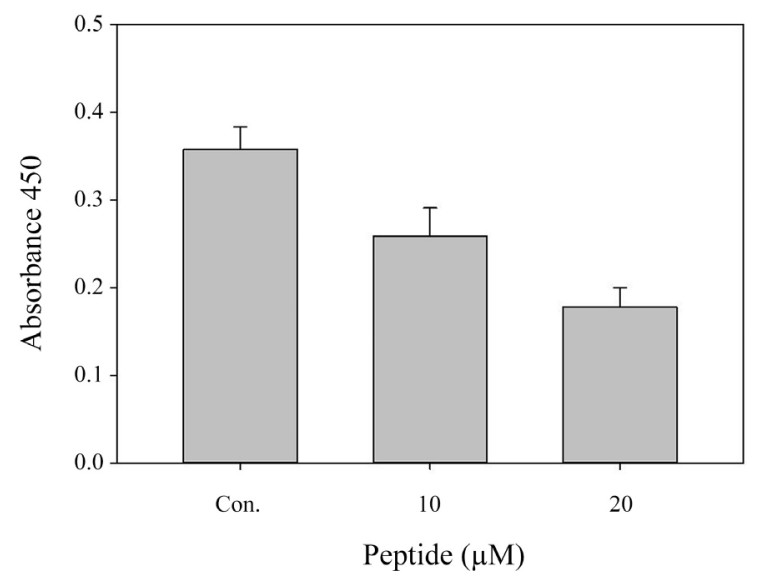

Figure 3. Proliferation of cells treated with cystatin C peptide. A BrdU incorporation assay was performed on melanoma cells untreated or treated with peptide at 10 and $20 \mu \mathrm{M}$. Assay was performed in triplicate.
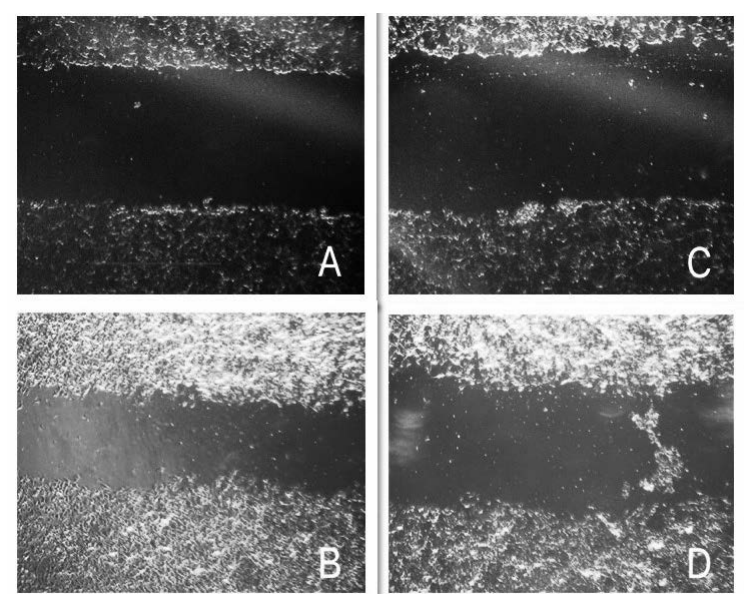

(a)

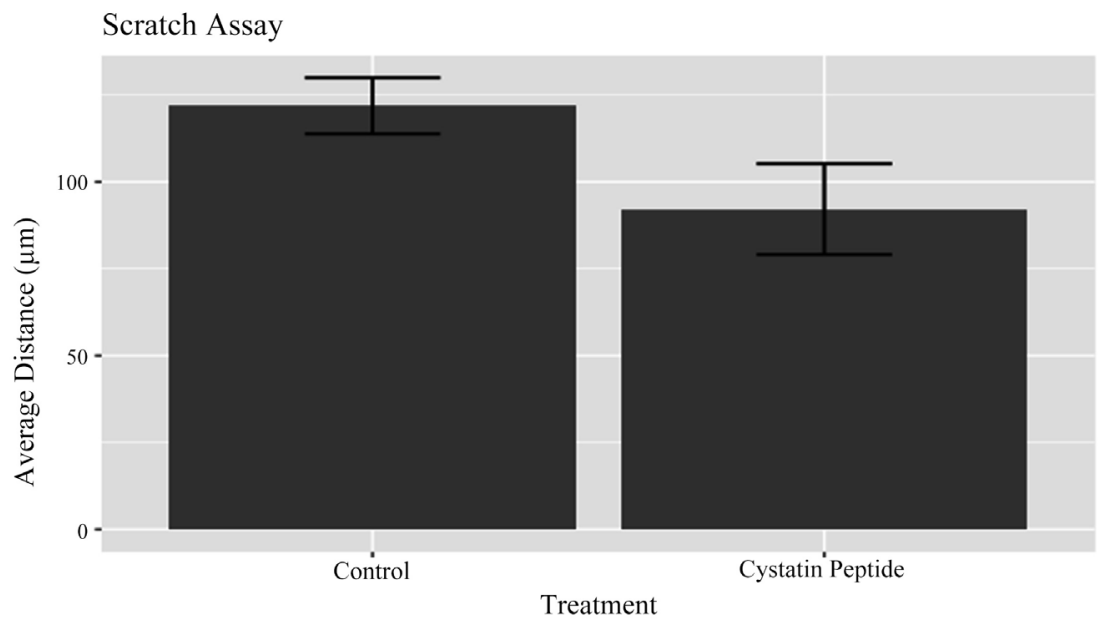

(b)

Figure 4. Cell migration of cells treated with cystatin peptide. (a) Representative scratches, A. control (scrambled peptide), 0 time. B. control, 24 hours. C. cystatin peptide, 0 time. D. cystatin peptide, 24 hours (magnification, $\times 4$ ). (b) Average distance cell migration $(\mu \mathrm{m})$ for quadruplicate scratches \pm s.e.m. 


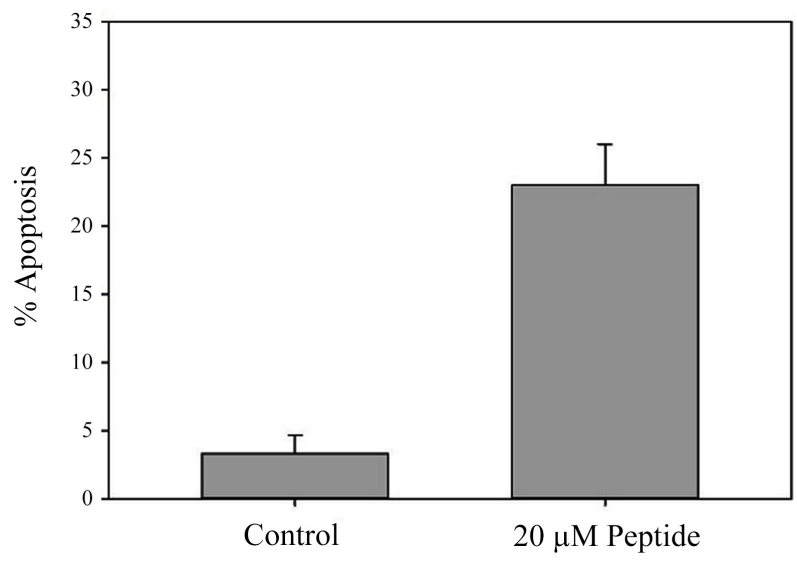

Figure 5. TUNEL assay of melanoma cells with or without peptide treatment. A TUNEL assay for melanoma cells treated without (control) or with cystatin peptide for 48 hours in culture. Percentage reported as TUNEL positive cells/total nuclei. Experiment was performed in triplicate with averages reported with s.e.m.

\section{Discussion}

There are few, if any, agents that are currently used to inhibit metastatic cells other than direct killing through chemotherapy or radiation. Metastatic melanoma cells are highly resistant to virtually all chemotherapeutic agents, most of which kill by apoptosis. We have described here a short cystatin C derived peptide that inhibits growth, migration, and induces apoptosis in metastatic B16 melanoma cells in vitro. Previous work by our laboratory has shown a small segment of the cystatin $C$ protein is required for inhibition of invasion and migration of B16F10 melanoma cells [8]. Another group previously described that melanoma cell signaling through activated Wnt5a/PKC pathway drives multiple aspects of melanoma metastasis including cell migration [12]. We therefore asked whether cystatin C over-expression could block PKC $\alpha$ activity, a downstream target of Wnt5a pathway activation. To serve as a marker for PKC $\alpha$ activity we examined pMARCKS level, a key substrate of PKC phosphorylation which is also involved mechanistically in melanoma cell migration [13]. Decreased MARCKS protein phosphorylation by cystatin overexpression clones confirmed cystatin was inhibiting PKC $\alpha$.

A short peptide was synthesized from cystatin $\mathrm{C}$ which spanned the conserved QVVAG region since this sequence was found to be critical for cystatin action on melanoma cells [8]. One advantage of a small peptide is that they can be delivered to cells in higher concentrations than most proteins. Another advantage of the cell penetrating peptide portion is that it may be taken up by cells by a different route than proteins which are mainly taken up by endocytosis [14]. In that case, cytoplasmic interactions of the peptide with protein targets would be much more efficient than for proteins (cystatin) which are endocytosed. At relatively low concentrations (5 - $20 \mu \mathrm{M}$ ), the cystatin peptide inhibits B16 melanoma cell growth, cell proliferation, migration, and induces apoptosis in vitro. 
Peptides have not traditionally been favored as therapeutic agents because of their short half-lives in vivo. One way to diminish extracellular degradation of peptides is to link them to cell penetrating peptides (CPPs) such that they are taken up by cells and removed from extracellular degradation [15]. The CPP dramatically increases the uptake of peptide while not showing cell toxicity itself, at least below $100 \mu \mathrm{M}$. Attachment of the cystatin peptide to a CPP can dramatically increase the efficiency of the cystatin peptide because better uptake occurs and the targets of the peptide are intracellular.

Metastasis requires cancer cell migration [16]. Previously it was shown inhibition of PKC $\alpha$ blocked cell migration for highly metastatic B16F10 melanoma [17]. We show here a small cystatin derived peptide inhibits B16F10 cell migration presumably through $\mathrm{PKC} \alpha$ inhibition. $\mathrm{PKC} \alpha$ drives cell migration through MARCKS protein activation as well as calcium channel regulation [13] [18]. Other cancer types however may not depend upon PKC signaling for cell migration. Whether the cystatin peptide can inhibit migration in other cell types requires further testing.

The cystatin peptide increased apoptosis of B16 melanoma cells in culture. Earlier work showed an increase in apoptosis in vivo upon overexpression of cystatin C in B16 melanoma [7]. A link between PKC $\alpha$ inhibition by cystatin and apoptosis occurs by PKC signaling through Akt, a critical cell survival pathway [19]. Down-regulation of anti-apoptotic factors such as Bcl-2 is another possible contributor to increased apoptosis seen with cystatin peptide. The actual cause of increased apoptosis induced by the cystatin peptide will require further study.

Two other anti-metastatic peptides have been described in the literature [20] [21]. The first peptide is derived from MARCKS protein and inhibits lung cancer metastasis. The second peptide is derived from an inhibitory region within PKC $\alpha$ and when delivered to mice was able to inhibit metastasis of breast cancer cells. Peptides may have roles as new therapeutic agents against metastatic disease. Efforts are currently underway in our laboratory to test cystatin peptide on melanoma metastasis in mice.

\section{Funding}

This work was funded by a Warner grant to J.L.C.

\section{Disclosures}

Patent \#9,567,369 to J.L.C. is disclosed concerning this work.

\section{Conflicts of Interest}

The authors declare no conflicts of interest regarding the publication of this paper.

\section{References}

[1] Ochieng, J. and Chaudhuri, G. (2010) Cystatin Superfamily. Journal of Health Care 
for the Poor and Underserved, 21, 51-70. https://doi.org/10.1353/hpu.0.0257

[2] Petushkova, A.I., Savvateeva, L.V., Korolev, D.O. and Zamyatnin Jr., A.A. (2019) Cysteine Cathepsins: Potential Applications in Diagnostics and Therapy of Malignant Tumors. Biochemistry (Moscow), 84, 746-761. https://doi.org/10.1134/S000629791907006X

[3] Cox, J.L., Sexton, P.S., Green, T.J. and Darmani, N.A. (1999) Inhibition of B16 Melanoma Metastasis by Overexpression of the Cysteine Proteinase Inhibitor Cystatin C. Melanoma Research, 9, 369-74. https://doi.org/10.1097/00008390-199908000-00005

[4] Kopitz, C., Anton, M., Gansbacher, B. and Krüger, A. (2005) Reduction of Experimental Human Fibrosarcoma Lung Metastasis in Mice by Adenovirus-Mediated Cystatin C Overexpression in the Host. Cancer Research, 65, 8608-8612. https://doi.org/10.1158/0008-5472.CAN-05-1572

[5] Alvarez-Diaz, S., Valle, N., García, J.M., Peña, C., Freije, J.M.P. and Quesada, V. (2009) Cystatin D Is a Candidate Tumor Suppressor Gene Induced by Vitamin D in Human Colon Cancer Cells. Journal of Clinical Investigation, 119, 2343-2358. https://doi.org/10.1172/JCI37205

[6] Sokol, J.P., Neil, J.R, Schiemann, B.J. and Schiemann, W.P (2005) The Use of Cystatin $\mathrm{C}$ to Inhibit Epithelial-Mesenchymal Transition and Morphological Transformation Stimulated by Transforming Growth Factor-Beta. Breast Cancer Research, 7, Article No. R844. https://doi.org/10.1186/bcr1312

[7] Ervin, H. and Cox, J.L. (2005) Late Stage Inhibition of Hematogenous Melanoma Metastasis by Cystatin C Over-Expression. Cancer Cell International, 5, Article No. 14. https://doi.org/10.1186/1475-2867-5-14

[8] McIntire, S.a.J.C. (2015) The Effect of Cystatin C Construct Clones on B16F10 in Vitro Cell Behavior. Journal of Molecular Biochemistry, 5, 4-11.

[9] Derossi, D., Calvet, S., Trembleau, A., Brunissen, A., Chassaing, G. and Prochiantz, A. (1996) Cell Internalization of the Third Helix of the Antennapedia Homeodomain Is Receptor-Independent. Journal of Biological Chemistry, 271, 18188-18193. https://doi.org/10.1074/jbc.271.30.18188

[10] Porstmann, T., Ternynck, T. and Avrameas, S. (1985) Quantitation of 5-Bromo2-Deoxyuridine Incorporation into DNA: An Enzyme Immunoassay for the Assessment of the Lymphoid Cell Proliferative Response. Journal of Immunological Methods, 82, 169-179. https://doi.org/10.1016/0022-1759(85)90236-4

[11] Shang, H-S., Chang, C.-H., Chou, Y.-R., Yeh, M.-Y., Au, M.-K., Lu, H.-F., et al. (2016) Curcumin Causes DNA Damage and Affects Associated Protein Expression in HeLa Human Cervical Cancer Cells. Oncology Reports, 36, 2207-2215. https://doi.org/10.3892/or.2016.5002

[12] Dissanayake, S.K., Olkhanud, P.B., O'Connell, M.P., Carter, A., French, A.D., Camilli, T.C., et al. (2008) Wnt5A Regulates Expression of Tumor-Associated Antigens in Melanoma via Changes in Signal Transducers and Activators of Transcription 3 Phosphorylation. Cancer Research, 68, 10205-10214.

[13] Chen, X.Y. and Rotenberg, S.A. (2010) PhosphoMARCKS Drives Motility of Mouse Melanoma Cells. Cellular Signalling, 22, 1097-1103.

https://doi.org/10.1016/j.cellsig.2010.03.003

[14] Ruczynski, J., Wierzbicki, P.M., Kogut-Wierzbicka, M., Mucha, P., Siedlecka-Kroplewska, K. and Rekowski, P. (2014) Cell-Penetrating Peptides as a Promising Tool for Delivery of Various Molecules into the Cells. Folia Histochemica et Cytobiologica, 52, 257-269. https://doi.org/10.5603/FHC.a2014.0034 
[15] Raucher, D. and Ryu, J.S. (2015) Cell-Penetrating Peptides: Strategies for Anticancer Treatment. Trends in Molecular Medicine, 21, 560-570. https://doi.org/10.1016/j.molmed.2015.06.005

[16] Lambert, A.W., Pattabiraman, D.R. and Weinberg, R.A. (2017) Emerging Biological Principles of Metastasis. Cell, 168, 670-691. https://doi.org/10.1016/j.cell.2016.11.037

[17] Sullivan, R.M., Stone, M., Marshall, J.F., Uberall, F. and Rotenberg, S.A. (2000) Photo-Induced Inactivation of Protein Kinase Calpha by Dequalinium Inhibits Motility of Murine Melanoma Cells. Molecular Pharmacology, 58, 729-737. https://doi.org/10.1124/mol.58.4.729

[18] Ziemba, B.P. and Falke, J.J. (2018) A PKC-MARCKS-PI3K Regulatory Module Links $\mathrm{Ca}^{2+}$ and $\mathrm{PIP}_{3}$ Signals at the Leading Edge of Polarized Macrophages. PLoS ONE, 13, e0196678. https://doi.org/10.1371/journal.pone.0196678

[19] Li, W., Zhang, J.C., Flechner, L., Hyun, T., Yam, A., Franke, T.F., et al. (1999) Protein kinase C- $\alpha$ Overexpression Stimulates Akt Activity and Suppresses Apoptosis Induced by Interleukin 3 Withdrawal. Oncogene, 18, 6564-6572. https://doi.org/10.1038/sj.onc.1203065

[20] Chen, C.H., Thai, P., Yoneda, K., Adler, K.B., Yang, P.-C. and Wu, R. (2014) A Peptide That Inhibits Function of Myristoylated Alanine-Rich C Kinase Substrate (MARCKS) Reduces Lung Cancer Metastasis. Oncogene, 33, 3696-706. https://doi.org/10.1038/onc.2013.336

[21] Kim, J., Thorne, S.H., Sun, L., Huang, B. and Mochly-Rosen, D. (2011) Sustained Inhibition of PKC $\alpha$ Reduces Intravasation and Lung Seeding during Mammary Tumor Metastasis in an in Vivo Mouse Model. Oncogene, 30, 323-333. https://doi.org/10.1038/onc.2010.415 